\title{
IV. The electrical resistance of selenium cells
}

\section{Shelford Bidwell M.A. LL.B.}

To cite this article: Shelford Bidwell M.A. LL.B. (1883) IV. The electrical resistance of selenium cells , Philosophical Magazine Series 5, 15:91, 31-35, DOI: $10.1080 / 14786448308627303$

To link to this article: http://dx.doi.org/10.1080/14786448308627303

曲 Published online: 28 Apr 2009.

Submit your article to this journal

Џ Article views: 3

Q View related articles $₫$ 


\section{$\left[\begin{array}{ll}31 & 1\end{array}\right.$}

IV. The Electrical Resistance of Selenium Cells. By Shelford Bidweld, M.A., LL.B.*

TN June 1881 a paper was read before the Physical Society 1 by Dr. Moser, on " the Microphonic Action of Selenium Cells." In this paper a very ingenious attempt was made to show that the effect of light in reducing the electrical resistance of selenium might be accounted for on perfectly well understood principles, without assuming the existence in the case of this substance of some law or property suigeneris and hitherto unobserved.

Dr. Moser's theory is shortly as follows :-There is always imperfect contact between the metallic electrodes and the selenium which together constitute a so-called "selenium cell." Selenium reflects the invisible portions of the spectrum, absorbing principally the visible or illuminating rays : the vibrations thus taken up assume the form of heat; and the temperature of the selenium cell is thereby raised†. In consequence of this rise of temperature the selenium expands; it is accordingly pressed into closer contact with the electrodes, and, as in the case of the microphone, the resistance of the system is proportionately diminished. When the cell is screened from the light, the absorbed heat is quickly radiated away; the selenium contracts to its former volume, and the original degree of resistance is restored. Thus, according to Dr. Moser's paper, the whole mystery is easily and completely explained.

This theory can evidently be submitted to a very simple and conclusive test. If it is true that the observed effects are due merely to a rise of temperature, then it is clearly immaterial whether such rise of temperature is brought about by the heating action of light or by the direct application of heat in the ordinary way. Instead of exposing a selenium cell to the light, let it be enclosed in a dark box and warmed over a gas-burner; then, if the theory be correct, the resistance of the cell should at once begin to fall. This, however, is not found to be the case. I have in my possession a number of selenium cells the resistance of which is immediately diminished by the smallest accession of light; but in the case of all of them (except one, of which I shall say more presently) the immediate effect of the direct application of heat is not a a fall, but a rise in the resistance. When the temperature of the cell reaches a point which is in general a few degrees

* Communicated by the Physical Society, having been read at the Meeting on November 25, 1882.

† "Selenium," Dr. Moser says, "is heated by light." 
higher than the average temperature of the air a maximum resistance is attained; and if the heating is continued, the resistance begins to decrease.

I gave a short account of this phenomenon in the 'Philosophical Magazine' of April 1881. Since this was published, I have made further and very careful experiments, the results of which are shown in the curves, figs. 1, 2, and 3.

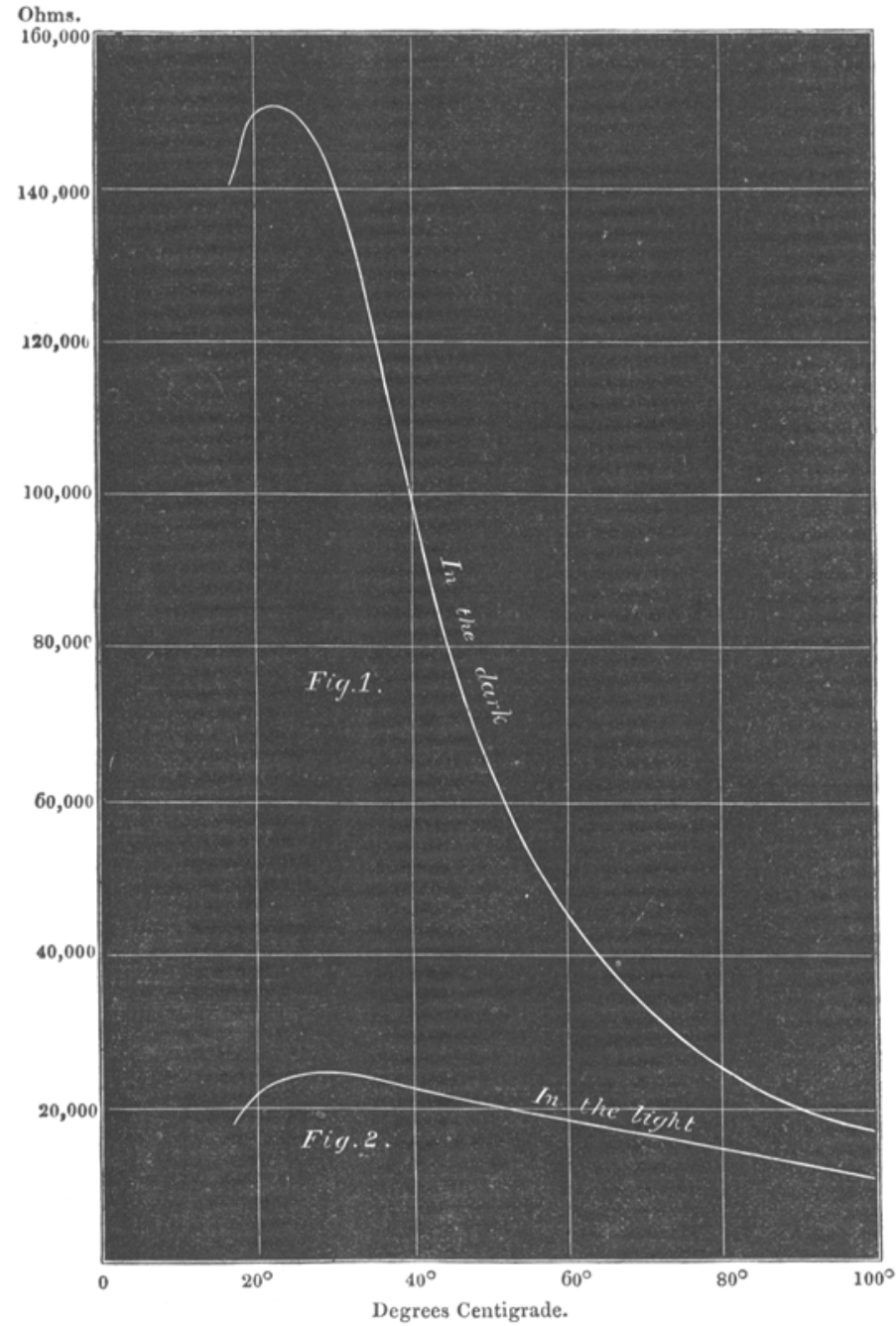

A selenium cell was placed in an air-bath in absolute dark- 
ness, the bulb of a thermometer being very near its surface. The temperature of the air was $17^{\circ} \mathrm{C}$., and the resistance of the cell at the beginning of the experiment was 140,000 ohms. The bath was then very slowly heated, and the resistance measured at every degree. At first the rise was very rapid (see fig. 1); then more gradual until the temperature reached $23^{\circ}$, when the maximum resistance of 150,000 ohms was attained. With conti- 180,000 nued heating the resistance fell, slowly at first, then more rapidly, then again slowly (as shown by the curve), the final measurement at $100^{\circ}$ being only 16,000 ohms*.

The same cell was afterwards submitted to the combined action of heat and light. A glass beaker was fitted with a wooden cover, to which the selenium cell was attached so as to hang perpendicularly inside the beaker ; the beaker was placed in a sand-bath which was heated by a Bunsen

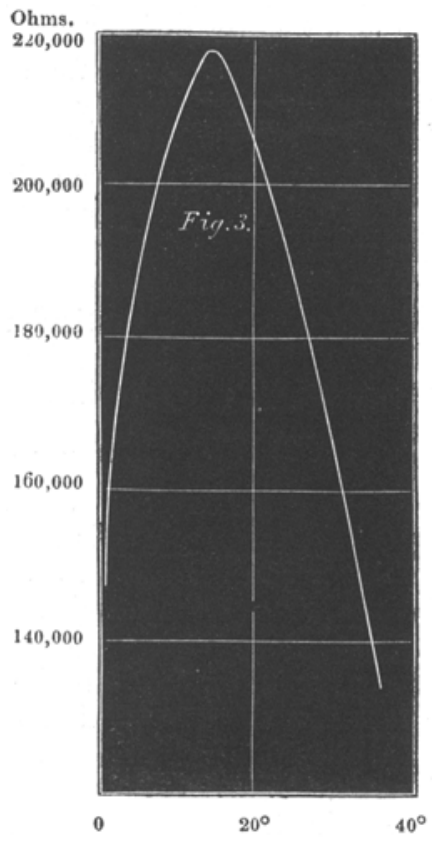
burner, and the cell was illuminated by a powerful paraffinlamp at a distance of 30 centimetres.

At $18^{\circ}$ its resistance was only $19,000 \mathrm{ohms}$ (see fig. 2). As in the former case, the first application of heat was accompanied by a rise, though smaller and more gradual than before, the maximum of $24,000 \mathrm{ohms}$ occurring at about $29^{\circ}$. The fall which followed was also very gradual, the resistance at $100^{\circ}$ being $10,000 \mathrm{ohms}$, or only 14,000 less than the maximum, as against a difference of 140,000 in the former experiment.

In these experiments it might possibly be suspected that the initial small rise of resistance is due to some accidental disturbing cause, and does not point to any essential characteristic of selenium, or rather perhaps of selenium cells. The following experiment seems, however, to settle the point conclusively. One of my selenium cells (the exceptional one

* When the cell was removed from the air-bath, its resistance in the dark in air at $18^{\circ}$ was found to have increased to 90,000 ohms.

Phil. Maǵ. S. 5. Vol. 15. No.91. Jan. 1883. 
above referred to) did not at ordinary temperatures exhibit this peculiarity. When heated, its resistance at once went down without any preliminary rise. This cell was placed in air at a temperature of $0^{\circ}$, and after remaining for half an hour its resistance was found to be 147,000 ohms. The temperature was then slowly raised; and, as I expected, the resistance at first went up, attaining a maximum of $219,000 \mathrm{ohms}$ at $13^{\circ}$, after which it went down to 134,000 ohms at $36^{\circ}$, when the experiment was stopped. The curve fig. 2 , which is on the same scale as the others, shows the results in a very striking manner, altogether excluding the possibility of accidental disturbance. This particular cell differed from others only in the fact that it acquired its maximum resistance at a temperature slightly below instead of slightly above the average temperature of the air.

The supposition that light produces its effect by heating is further negatived by the fact, that a comparatively high degree of temperature is required to bring down the resistance of the cell to the point to which it is instantly reduced by exposure to a strong light. When a selenium cell is for a moment exposed to sunlight, it does not become perceptibly warm to the touch; but the amount of dark heat necessary to effect the same reduction in its resistance as is caused by a moment's sunshine would certainly render it too hot to handle.

Again, those who have experimented with the photophone know well that the best results are obtained only when precautions are taken to exclude those rays which are especially instrumental in producing heat, as by filtering the beam of light through a solution of alum. Dark radiation does indeed per se diminish the resistance of selenium; but the diminution due to dark radiation is to some extent masked by the rise of temperature which accompanies it, and which generally tends to produce the opposite effect.

To me it seems clear that the electrical effects of radiation are, in this case at least, no more due to the intermediate action of temperature than are the chemical effects which radiation sometimes produces, as in the various photographic processes. All such effects are no doubt ultimately of a mechanical nature; but while increased temperature may result from vibrations the periodicity of which vary between very wide limits, the other effects arise only when there is some more or less definite relation between the period of the æther-waves and the molecular constitution of the substance upon which they act. 
In its peculiar sensitiveness to the visible part of the spectrum selenium seems, so far as our present knowledge goes, to stand almost, if not quite, alone*.

Riverstone Lodge, Southfields,

Wandsworth, S.W.

V. On Central Forces and the Conservation of Energy. By Walter R. Browne, M.A., M. Inst. C.E, late Fellow of Trinity College, Cambridge $\dagger$.

$\mathrm{T} T$ is well known that the ordinary proof of the principle 1 known as the Conservation of Energy assumes the forces acting to be Central Forcesł; but the intimate connexion existing between these two facts-the existence of Central Forces and the Conservation of Energy-has not, so far as $I$ am aware, been thoroughly examined. I shall here attempt to show that the two necessarily imply each other; so that not only is the Conservation of Energy true if the system is a system of central forces, but the Conservation of Energy is not true if the system is any thing but a system of central forces.

For the sake of simplicity I will confine myself to the case of two particles, and suppose them so far apart, in proportion to their dimensions, that each may be treated as if concentrated at its centre of gravity. Let the particles be $A$ and $B$, and consider the motion of $B$ with reference to $A$ as fixed. Suppose $B$ to be moving away from $A$, and to be acted upon by a moving force due to the action of $A$. Let it move from a distance $a$ to a distance $a+b$, and let $\mathrm{F}$ be the resolved part of the moving force in the line $\mathrm{AB}$. Then the energy exerted by $B$ during this motion in overcoming the attraction of $A$ is represented by

$$
\int_{a}^{a+b} \mathrm{~F} d x .
$$

Let $v_{1}$ be B's initial velocity, $m$ its mass. Then at the end of the motion $v_{1}$ will be reduced to $v$, where $v$ is given by the

* So far as regards Dr. Moser's application of his theory to the carbon photophone of Messrs Bell and Tainter, I entirely agree with him; my own experiments showing conclusively that the effects are due to heat only. But the best carbon cells are vastly inferior in their action to those of selenium.

$\dagger$ Communicated by the Physical Society, having been read at the Meeting on November 11, 1882.

t This is recognized explicitly by Clausius, 'Mechanical Theory of Heat,' p. 16. 